Peer e-Tutoring: Effects on students' participation and interaction style in online courses 


\section{Peer e-Tutoring: Effects on students' participation and interaction style in online courses}

Abstract

In this paper, we describe a procedure to promote active participation in online courses by supporting students in performing the role of an e-Tutor during group activities. A case-study, conducted to explore the procedural effects both on students' interactions and on their perceptions about the role, is discussed. Eighteen university students (67\% female, Mean Age $=23$ years) took part in online collaborative learning activities as part of a 15 week blended learning course. Twelve participants took turns in covering the role of e-Tutor. Findings were based on a mixed methods analysis of 7,105 contributions posted online by the 18 students. An analysis of e-Tutor self-assessment forms was also considered. Results indicated that utilizing peer-based e-Tutors promoted substantial active participation in online discussions. Moreover, students performing the role of e-Tutor adopted a supportive, collaborative and educational style, which was maintained even after their turn as e-Tutor had ended.

Keywords: e-Learning, e- Tutor, Role Taking, students' active role 


\section{Introduction}

'Role Taking' (RT) is a specific type of collaboration script (Dillenbourg, 2002), which consists of an explicit didactic contract between a teacher and a group, and is based on the distribution of learning responsibilities during collaborative learning activities. Recently, RT as a didactic practice has seen widespread use in virtual environments (Strijbos et al., 2007; Weinberger, 2008).

Many roles can be designed in order to support constructive interaction and facilitate learning. One such role is that of an e-Tutor. An e-Tutor is an individual who facilitates effective knowledge building via supportive interactions with learners in collaborative virtual learning environments (Kopp, Matteucci \& Tomasetto, 2012). Traditionally, the role of an e-Tutor is afforded to the teacher or instructor of a student group. In the case-study here described, we observe the impact of using peer eTutors on students' participation and interactions in a blended university course.

\section{Theoretical Background}

Careful structured activities and appropriate facilitation are needed to support students' involvement and participation in online courses (Fischer et al., 2013). A collaborative script consists of a series of instructions that prescribes how students should interact and collaborate, based on specific pedagogical models.

RT can be considered as a specific type of collaboration script. Each role (e.g. moderator, summarizer, and problem-solver) defines how classmates should behave, by outlining functions and responsibilities that are kept for a certain period. Roles can be conceived as both a method and as a goal. As a method, roles are used to structure teamwork; as a goal, they allow students to develop critical skills. For this reason, it is important to have a rotation of roles, so that each student can experience the skills associated with the various roles performed. 
The role of e-Tutor is usually regarded as a crucial figure within online learning contexts. Many researchers have described the general skills needed to perform the role of an e-Tutor (Berge \& Collins, 1996; Edwards et al., 2011; Salmon, 2000). An e-Tutor's skills profile depends on several factors including educational context, the number of learning participants, the features of the online environment and the type of learning content available. In summary, e-Tutors have been described as:

- Instructors: high technical knowledge, performing the role mainly by giving instruction to consult or download materials, "one to many" communication;

- Facilitators: communication and interpersonal skills, monitoring collaborative activities, providing individual support, "one to one" communication;

- Moderators: skills related to group dynamics such as ensuring respect of netiquette, facilitating focused and stimulating discussions, maintaining a favorable climate for all participants; "many to many" communication.

Traditionally, it has been the prerogative of instructors and teachers' assistants to perform the role of an e-Tutor, mirroring the traditional teacher-led learning models of classrooms worldwide. Research has suggested, however, that adopting peer-tutorship, an educational framework in which senior and expert students support their peers in performing requested activities, has the capacity to promote the distribution of responsibility for learning (Topping, 2008) and provide academic benefits in both classrooms (Bowman-Perrott, Davis, Vannest \& Williams, 2013) and virtual environments (Evans \& Moore, 2013). Furthermore, peer tutoring can itself be considered a useful and empowering learning activity for the peer e-Tutors' (Topping, 2008).

Here, we introduce the idea of entrusting the role of e-Tutor to students to sustain their active and constructive participation in a 15-week blended university course.

\section{Research Aims}


The general aim of this study is to describe a procedure through which students enact the role of an e-Tutor as a means to support constructive and active participation in an online learning environment. We observed how this role was performed and perceived by 12 students participating in a blended university course. Specifically, our research questions are:

- How does performing the role of e-Tutor affect the way university students interact and participate in a blended course?

- How do students perceive the effectiveness of playing the role of an e-Tutor in terms of participation in a course?

\section{Method}

\section{Context and participants}

The research focusses on the level of active and constructive participation of students partaking in a 15-week blended learning course at the University of Bari in Italy. Eighteen students (67\% female, mean age: 23 years) participated in the course and were divided into three groups; groups 1 and 2 were composed of seven students, with six students in group 3. Students completed six modules in total during the course. For four of the modules, different peer e-Tutors were assigned from each group. In total 12 students ( 7 female, 5 male) took turns in the role of e-Tutor.

The course content and delivery for this study are based on the "Blended Collaborative and Constructive Participation" (BCCP) model (Ligorio et al., 2010). The model attempts to overcome the mere alternation of on- and offline learning, introducing a carefully designed integration between online and offline contexts (see "Course activities" for further details about the model). The BCCP model has been applied to deliver specialist courses on E-Learning Psychology for Work Psychologists over the last ten years.

Participation in online activities during the course modules took place on a voluntary basis. Online activities could be partaken on any type of online platform that allowed discussion, uploading 
and downloading of different kinds of materials.

\section{Course activities}

In line with the BCCP procedural model (Ligorio et al., 2010), each module began with an offline lesson, during which the teacher introduced the learning content of the module and assigned learning materials to each student in the three groups. The teacher led lecture ended with a research question aimed at guiding all of the activities related to the module. In addition, during the first module, a professional e-Tutor modelled the best practices associated with the role, outlining tasks, responsibilities and actions that an e-Tutor should usually undertake.

Throughout the assigned modules all students completed the following tasks:

- $\quad$ studied the assigned learning material and wrote an individual review,

- posted reviews online; read and commented on reviews from other members of their group,

- discussed the research question, searching for a common shared answer;

- created collaborative products, such as conceptual maps summarizing the content of the module.

For each module, one student per group in turn performed the role of an e-Tutor for their respective group. The e-Tutors were in charge of monitoring and supporting the discussions in their groups by inviting everyone to participate, keeping the discussion focused on the research question, guiding the module and reinforcing deadlines. Moreover, to promote socialization and distribution of the role, an "e-Tutors' web-forum" was created in which students from different groups could collect reflections, proposals and concerns about being an e-Tutor. At the end of each module, outgoing eTutors were invited to post comments about their experience, so as to support the upcoming students taking the role for subsequent modules. They were also required to complete a self-assessment sheet 
which contained three positively anchored questions (coded as $0=$ not at all to $4=$ very much) in which students assessed how much the role of e-Tutor had impacted their learning experience in terms of participation to the activities, content learning, and skills acquisition.

The activities outlined in the procedure here described aim to provide a means of supporting positive interaction, knowledge building and a sense of students challenging themselves (Ligorio \& Sansone, 2009). The distinctive features of the procedure are:

- a learning by doing perspective (Aldrick, 2005) in a highly ecological learning environment and based on authentic tasks;

- making clear the specific tasks and abilities associated to the role, by giving adequate instruction;

- an initial modelling from a professional e-Tutor, yet promoting a personalized interpretation of the role;

- peer-modeling based on the rotation of the role across the modules and the sharing of meta-cognitive reflections about the role within a specific online space.

\section{Data Analysis}

A case-study approach was used to analyze data from the online posts $(\mathrm{N}=5,254)$ made by the students selected to be e-Tutors for the duration of the course, comparative posts made by students who did not perform the role of e-Tutor $(\mathrm{N}=1,851)$ and the e-Tutor self-assessment sheets $(\mathrm{N}=48)$ completed at the end of each course module. Despite a small physical student sample size, it should be noted that 15-weeks of student's online posts, together with a modest collection of e-Tutor selfassessments, provides a large data set from which a mixed methods analysis can be drawn, combining both qualitative and quantitative report (Kelle, 2006).

For the quantitative analysis, each e-Tutor student's posts were collated along with the posts written by their respective group members for the duration of the course. Descriptive statistics and chi- 
square differences were calculated. This analysis was used to indicate if RT affected students' participation.

For the qualitative analysis of students' posts, a content analysis on the dataset generated by each of the students was undertaken. A study specific coding scheme was developed following Grounded Theory (Corbin \& Strauss, 2007). Two independent researchers analyzed a sample of 100 posts by developing a primary coding scheme. A unit of analysis was considered a 'unit of meaning' (Chi, 1997), that is a set of sentences referring to the same meaning. Within the 7,105 posts, the coders identified 15,222 units of meaning. Subsequently, the researchers compared their results in order to discuss controversial cases and reach consensus about both the attributions and the coding scheme. When contradictory concepts could not be solved, a third researcher was consulted. All of the researchers involved in the procedure received specific training about the aim of the research and the concepts inquired through the coding.

A five-category coding system, reported in Table 1, was finalized. For each category, one or more indicators were singled out and connected to the content retrieved in the utterance. Once the coding scheme had been established, the two researchers applied it independently to the dataset, assigning the corresponding category. Differences were discussed and negotiated, reaching an interreliability of 0.91 . After coding all the data, occurrences and means were calculated for each module. This analysis was essential to understand the interaction style students enacted during the course modules.

\section{$<$ place Table 1 here $>$}

Finally, descriptive statistics were produced for the e-Tutor self-assessments. Differences between the e-Tutor's responses were calculated using $\mathrm{t}$ and F-tests. This analysis provided an indication of the students' perceptions about their RT experiences.

Evolution of students' participation 
The quantitative analysis of the students' posts revealed that each of the 12 student e-Tutors reached the peak of their own participation when covering the role of the e-Tutor. Figure 1 shows students' standard participation (i.e. their average participation during the modules in which they were not yet or no longer covering the role), compared to their average participation during their RT experience.

$<$ place Figure 1 here $>$

The figure shows how students' participation in the learning activities always increased, when covering the role of e-Tutor $\left(\chi^{2}=38.25 ; \mathrm{p}<0.001\right)$. It would appear therefore that, on this occasion, RT was a successful device in increasing learners' participation.

Increasing participation is not an end in itself, but it is a means to achieve additional goals. Researchers have demonstrated that a higher level of participation is beneficial also to improve the quality of discussions and to foster the sense of online community (Kollar, Fischer \& Slotta, 2007). This theory seems to be supported by the following reflections posted online by Daniela, immediately after she had completed her turn in the e-Tutor role:

Excerpt n. 1, “Tutors' forum”; note n. 3.404, Daniela.

Personally, I feel more and more engaged! And this motivation is, on one side, related to the presence of the group (I try to "do my best", not only to improve myself, but also to support the growth of my group!). On the other hand, I become more aware of my own abilities (organizational and relational skills, critical approach, etc.), thanks to the possibility to engage in a role requiring various skills and responsibilities! I think that this increased motivation makes higher the quality of our products.

Daniela perceived a growing engagement and motivation that she attributes, on one side, to 'presence of the group' and, on the other side, to an increasing awareness of her own abilities, which are seen as strictly linked to performing 'a role requiring various skills and responsibilities'. The sense of responsibility leads this student to do her best ('not only to improve myself, but also to support the growth of my group!'). Finally, she considered the increased motivation as the main leverage of the 
growing quality of the products collaboratively constructed by the group.

Through the qualitative analysis of the students' posts, we wanted to understand if and how the e-Tutor role influenced our students' interactions style. Since no significant difference between males and females has been traced, we compared the general mean of each category before, during and after the students covered the role (see Fig.2).

<place Figure 2 here $>$

Before adopting the role of e-Tutor, students displayed an interactive style mainly characterized by emotional (24\%), supportive (21\%) and collaborative (19.2\%) interactions. Organizational (17.2\%) and educational $(18.1 \%)$ posts were the less frequent. When performing the role of e-Tutor, the students' emotional and organizational interventions decreased (from $24 \%$ to $10.8 \%$, from $17.2 \%$ to $15.8 \%$ ). However, the students became more supportive (from $21 \%$ to $25.8 \%$ ), collaborative (from $19.2 \%$ to $22.3 \%$ ) and educational, that is to say more content-oriented (from $18.1 \%$ to $25.3 \%$ ). Following on from their turn in the role of e-Tutor, posts from subsequent modules observed a further increase of supportive (from $25.8 \%$ to $27.7 \%$ ) and collaborative (from $22.3 \%$ to $24.1 \%$ ) interactions, with a slight decrease of educational posts (from $25.3 \%$ to $22.9 \%$ ). Emotional and organizational interactions were still low, respectively going from $15.8 \%$ to $13.7 \%$ and from $10.8 \%$ to $11.6 \%$.

Based on these results, we claim that during this course the students seemed to be influenced by RT. The frequencies of the categories concerning supportive, educational and collaborative styles of interaction changed positively and active participation appeared to be promoted. The decrease in the organizational category of interactions (from $17.2 \%$ to $10.8 \%$ ), might be explained by the growing confidence our students gained about the course, its structure and tasks, which may consequently have decreased worry about organizational issues. The emotional category of posts was initially the most frequent one, but it decreased during and after the role taking exercise (from $24 \%$ to $11.6 \%$ ). As this category (see Table 1) refers to moods and feelings, it may have decreased due to changes in the 
perceptions relating to the online platform over time. At the beginning of the course, indeed, most of the emotions expressed were related to frustrations experienced in using the online platform ("I'm $a$ bit frustrated and confused about this platform $\odot$ ”). As their familiarity with the platform increased and their commitment to performing the role of an e-Tutor became their focus, emotional expressions waned in favor of posts pertaining to educational content and collaborative practices. It should be noted that we consider the change in emotional expressions to be neither positive nor negative per se. We consider students expressing their emotions at the outset of the course positively because, when shared and effectively managed, emotional expressions can aid both the individual and the group as a whole in growing as effective learners.

Furthermore, we analyzed the trends of the six students not covering the e-Tutor role (Fig.3). Looking at the figure, we notice that the supportive and educational categories remained rather stable for the duration of the course, whilst collaborative and emotional interventions tended to increase. Interestingly, the organizational category trend also decreased for the students not experiencing the eTutorship.

$<$ place Figure 3 here $>$

Considering the changes we observed in the students' interaction style while performing the role of e-Tutor, we believe some effects can be outlined. To be an e-Tutor, students have to be committed to tasks such as monitoring the discussion, sustaining group-mates with lower participation, and keeping up with the deadlines. The supportive and goal-oriented style was functional to these aims. An even more valuable effect is that these students kept this style after they had ended the role (see Fig.2). The following post was written during the fifth module by a student who had played the role three modules before:

Excerpt n. 2, “Group 3 - Research-question discussion”, Module n 5; note n. 3.612, Giovanni.

Michela, I know you're burdened with commitments at this time, nevertheless you are doing a 
lot, so I do not think you have to blame yourself if sometime you do not log in (-). Just post your summary by tomorrow and we will still be able to get the job done. Anyway we will wait for you to come back: without you, it is not the same on the platform!

This type of comment shows how a student no longer covering the role used the tutoring skills he had learnt previously to favor individual participation. It seems, therefore, that interaction styles could be considered as "residues" of the RT, positively influencing long-term collaborative strategies.

\section{Students' perceptions about role taking}

To fully understand the impact of the e-Tutor RT, we also analyzed how students themselves perceived their participation when covering the role. We report the results from the self-assessment sheets supported by representative qualitative excerpts from student' posts.

From the self-assessment sheets, we gathered how students assessed the impact of the e-Tutor role on participation, skills acquisition and content learning (Tab. 2):

\section{$<$ place Table 2 here $>$}

Specifically, students considered the role as mainly affecting their participation in the activities (3.7), followed by content learning (3.6) and skills acquisition (3.3). The following excerpt gives us some insight about the specific skills this student thinks to have improved:

Excerpt n.3, "Tutors' forum"; note n. 3.623, Claudio.

By taking the e-Tutor role, I think I have improved some of my relational abilities, but I've also begun to think in a time-management perspective, especially when my tasks and my colleagues depend on that. Also, I've realized something I didn't expect to: I'm well able to learn through interaction and collaboration in a team. Perhaps for this reason, my motivation grows day by day.

Apart from the skills this student has highlighted, we found particularly interesting the unexpected insight to which he refers: to be 'well able to learn through interaction and collaboration in a team' and, consequently, to feel his motivation growing. 
We have already noticed (Fig. 2) that in our case-study the e-Tutor RT experience is characterized by a general supportive and collaborative style. The excerpt reported below shows this student's awareness about such a style:

Excerpt n.5, “Tutors' forum”, Module 5; note n. 3.246, Valentina.

I think I've been able to be a point of reference for my group, also from an emotional point of view, encouraging the active participation of everybody, appreciating initiatives and insights, giving timely feedback .... proposing questions to reflect on ("would you introduce yourself differently in a digital environment? Why?"), trying to solve technical problems ... Above all, I felt enthusiastic in doing so and I think it was quite natural for me $\odot$.

This note contains a "summary" of the main typical skills featured in being a professional eTutor: being supportive with the group by encouraging active participation, appreciating initiatives and insights, giving timely feedback and sustaining collaboration by 'proposing questions to reflect on'. Furthermore, a good metacognitive attitude and a positive feeling ('I felt enthusiastic' and 'it was quite natural for me') can be recognized in the excerpt. This excerpt exemplifies the way in which the e-Tutors in this study took on board the 'best practices' ascribed to them in their introductory session with the professional e-Tutor, and used them to positively influence the learning and collaboration in their groups.

\section{Conclusion and further directions}

This case-study was inspired by the need to find ways in which to support students' active and constructive online participation. To accomplish such needs we have tried to develop a procedure to support students in taking the role of an e-Tutor, based on the RT idea of assigning the role in turn to different students - one for each module. Complementing the blended learning model, "Blended Collaborative and Constructive Participation" (Ligorio et al., 2010), the case-study analyzed concerned a blended university course, during which 12 students - out of the 18 in total attending the 
course - performed the role of an e-Tutor. Specifically, we wanted to understand the impact of RT on students' participation and perception.

We are fully aware that the small size of our sample, in terms of number of students covering the role of e-Tutor $(\mathrm{N}=12)$, does not allow generalization. Nevertheless, by analyzing the online posts ( $\mathrm{N}=5,254)$ of the e-Tutor students, and by comparison those posted by students not selected to be eTutors $(\mathrm{N}=1,851)$, we believe we have presented a substantial data set from which some conclusions can be drawn. A mixed methods analysis was conducted, combining the application of a study specific coding scheme, appropriate statistical measures and the comments on selected excerpts. In this way, we could combine different type of data and gather a multiple-perspective understanding of the impact of e-Tutor RT. In particular, the qualitative analysis allowed us to describe processes and strategies our students enacted when performing the e-Tutor role; whilst the quantitative analysis gave as an overview of how these strategies developed during the course.

Student e-Tutors not only increased their participation quantitatively with their group peers, but they also changed their style of interaction, by adopting and maintaining:

- a supportive style, stimulating their group-mates' participation and motivation;

- a collaborative style, perceiving the group as a means for learning;

- an educational style, focusing discussions on learning content and calling for further reflection.

We consider, in light of this case-study, that the procedure we developed in promoting peer based e-Tutor RT is quite effective in supporting and structuring online participation. We do acknowledge, however, that additional analysis is needed to confirm the trends found in our casestudy. Larger scale longitudinal data collection and analysis with a representative sample is recommended. Furthermore, we hope this research will inspire instructors and teachers to adopt the peer-based procedure we have developed in their own educational establishments and, subsequently, be able to verify if the same trends can be observed. 
The implications of this research are far reaching in the field of education and online learning. We therefore foresee many directions that our RT procedure may take in future research. In terms of our own future plans, we are currently seeking to investigate possible relations between participation and the enhancement of results in terms of learning outcomes. We also believe there is scope investigation of the peer based e-Tutor role and the RT procedure in terms of students' perceptions of measured educational motivation - through appropriate scales - in order to explore the correlations with value/usefulness, perceived competence and interest/enjoyment related to the role of e-Tutor.

\section{References}

Aldrich, C. (2005). Learning by Doing: A Comprehensive Guide to Simulations, Computer Games and Pedagogy in E-learning and Other Educational Experiences. San Diego: Pfeiffer

Berge, Z. \& Collins, M. (1996b). Facilitating Interaction in Computer Mediated Online Courses.

FSU/AECT Distance Education Conference, Tallahasee FL, giugno, 1996.

Bowman-Perrott, L., Davis, H., Vannest, K., Williams, L., Greenwood, C., \& Parker, R. (2013). Academic benefits of peer tutoring: A meta-analytic review of single-case research. School Psychology Review, 42(1), 39.

Brown, A.L. \& Campione, J.C. (1990). Communities of learning or a content by any other name. In D. Kuhn (ed.), Contribution to human development (108-126). New York: Oxford University Press.

Chi, M. T. H. (1997). Quantifying qualitative analysis of verbal data: A practical guide. The Journal of the Learning Sciences, 6, 271-315.

Corbin, J., \& Strauss, A. (2007). Basics of qualitative research: grounded theory procedures and techniques, 3rd edn, Sage, Newbury Park, CA

Dillenbourg, P. (2002). Over-scripting CSCL: The risks of blending collaborative learning with instructional design. In P.A. Kirschner (Ed.) Three worlds of CSCL. Can we support CSCL (6191). Heerlen: Open Universiteit Nederland.

Edwards M., Perry B., Janzen K., (2011). The making of an exemplary online educator, in "Distance Education”, vol. 32, n. 1, pp. 101-118. Routledge: Oxfordshire (UK).

Evans, M. J., \& Moore, J. S. (2013). Peer tutoring with the aid of the Internet. British Journal of 
Educational Technology, 44(1), 144-155.

Fischer, F., Kollar, I., Stegmann, K. \& Wecker, C. (2013). Toward a script theory of guidance in computer-supported collaborative learning, in Educational Psychologist 48, 1 (2013) 56-66

Kelle, U (2006). Combining qualitative and quantitative methods in research practice: purposes and advantages, Qualitative Research in Psychology, vol. 3, pp. 293-311

Kollar, I., Fischer, F., \& Slotta, J. D. (2007). Internal and external scripts in computer-supported collaborative inquiry learning. Learning and Instruction, 17(6), 708-721.

Ligorio, M.B. \& Sansone N. (2009). Structure of a Blended University Course: Applying Constructivist Principles to Blended Teaching. In Carla R. Payne (eds.) Information Technology and Constructivism in Higher Education: Progressive Learning Frameworks (216-230). Hershey, Pa: Igi Idea Group Inc.

Ligorio, M.B., Loperfido, F.F., Sansone, N. \& Spadaro, F. P. (2010). Blending educational models to design blended activities. In F. Pozzi \& D. Persico (Ed.) Techniques for Fostering Collaboration in Online Learning Communities: Theoretical and Practical Perspectives. Hershey, Pa: Igi Idea Group Inc.

Salmon, G. (2000). E-moderating: The key to teaching and learning online. London: Kogan Page.

Strijbos, J.W., Martens, R. L., Jochems,W. M. G. \& Broers, N. J. (2007). The effect of functional roles on perceived group efficiency during computer-supported collaborative learning: A matter of triangulation. Computers in Human Behavior, 23, 353-380.

Topping, K (2008). Peer-assisted learning: A practical guide for teachers. Newton, Mass.: Brookline Books.

Weinberger, A. (2008). CSCL scripts: Effects of social and epistemic scripts on computer supported collaborative learning. Berlin: VDM. 


\begin{tabular}{|c|c|c|}
\hline Categories & $\begin{array}{l}\text { Focus of the e- } \\
\text { Tutors' } \\
\text { interventions }\end{array}$ & $\begin{array}{c}\text { Indicators of tutoring } \\
\text { style }\end{array}$ \\
\hline 1.Supportive & $\begin{array}{l}\text { individuals and } \\
\text { their participation }\end{array}$ & $\begin{array}{l}\text { a) encouraging } \\
\text { participation } \\
\text { b) appreciating group- } \\
\text { mates' contribution }\end{array}$ \\
\hline 2.Educational & content and process & $\begin{array}{l}\text { c) keep the group } \\
\text { focused on the } \\
\text { learning discussion } \\
\text { d) invite for further } \\
\text { reflection } \\
\text { e) meta-cognitive } \\
\text { contributions on the } \\
\text { learning process } \\
\text { f) knowledge } \\
\text { construction }\end{array}$ \\
\hline 3.Collaborative & $\begin{array}{l}\text { group interaction } \\
\text { and collaborative } \\
\text { learning }\end{array}$ & $\begin{array}{l}\text { g) } \text { stimulating } \\
\text { collaboration by } \\
\text { inviting to share } \\
\text { tasks and } \\
\text { responsibilities } \\
\text { h) } \\
\text { offering help about } \\
\text { educational content }\end{array}$ \\
\hline 4.Organizational & timing and tasks & $\begin{array}{l}\text { i) giving/ } \\
\text { j) negotiating } \\
\text { information about } \\
\text { timing, tasks and } \\
\text { space management. }\end{array}$ \\
\hline 5.Emotional & $\begin{array}{l}\text { emotions and } \\
\text { relations }\end{array}$ & $\begin{array}{l}\text { k) informal talking } \\
\text { 1) showing emotions }\end{array}$ \\
\hline
\end{tabular}

Table. 1. The coding scheme 


\begin{tabular}{c|c|c|c}
$\begin{array}{l}\text { How much did the role you have } \\
\text { just performed impact on: } \\
(0=\text { not at all; 4=very much) }\end{array}$ & $\begin{array}{c}\text { Participation to } \\
\text { the activities }\end{array}$ & $\begin{array}{c}\text { Skills } \\
\text { acquisition }\end{array}$ & Content learning \\
\hline E-Tutor & $\mathbf{3 . 7}$ & $\mathbf{3 . 3}$ & $\mathbf{3 . 6}$
\end{tabular}

Table. 2. Students' perception of the impact of the e-Tutor role 
Figure 1: Students' participation while performing the e-Tutor role compared to their standard participation.

Figure 2. Distribution of the five categories before, during and after the RT

Figure 3. Participation of students not covering the e-Tutor role 